\title{
Local anaesthesia for 1221 vitreoretinal procedures
}

\author{
R S B Newsom, A C Wainwright, C R Canning
}

\begin{abstract}
Background-Vitreoretinal (VR) surgery has been increasingly performed under local anaesthesia (LA) in this unit. The results of an audit monitoring this change are presented.

Methods-Data were collected on 1497 patients including type, volume, and position of the anaesthetic block, type of surgery, complications, and patient reactions.

Results-1221/1479 (82\%) patients had LA. They were older than those having general anaesthesia (GA) 63.5 years $v 45.9$ years; $146(10.6 \%)$ blocks were intracone, 130 $(10.6 \%)$ peribulbar, and $927(75.9 \%)$ combined. Operations included 436 vitrectomies, 545 retinopexy with or without vitrectomy, and 238 buckling procedures. Some pain was felt by $9.4 \%, 8.8 \%$, and $19.7 \%$ of patients during vitrectomy, retinopexy with or without vitrectomy, and buckling surgery respectively.

Conclusion-Local anaesthesia for VR surgery is well tolerated by patients, being effective throughout longer and more stimulating ocular surgery.

(Br F Ophthalmol 2001;85:225-227)
\end{abstract}

For many ophthalmic surgeons local anaesthesia (LA) has become the preferred option over general anaesthesia (GA) because of quicker patient rehabilitation and the avoidance of possible complications from general anaesthesia. ${ }^{1-3}$

Several methods of LA for vitreoretinal (VR) cases have been described, including retrobulbar, ${ }^{4-9}$ peribulbar, ${ }^{8-11}$ sub-Tenon's, ${ }^{12}{ }^{13}$ and even topical anaesthesia in some cases. ${ }^{14} 15$ In several countries $85-90 \%$ of VR surgery is carried out under LA. However, this is not the case for VR surgery in the UK. ${ }^{4}$ Reluctance to use LA for VR surgery may stem from the longer, more unpredictable and uncomfortable nature of VR surgery.

In our unit LA has been introduced over the past 6 years and has increased in use from $12 \%$ to $96 \%$ in January to 1 February 2000 . An audit of LA for VR surgery was performed over this transition period and the data presented in this paper are a summary of this experience.

\section{Methods}

Data were collected prospectively on 1497 consecutive patients undergoing VR surgery, over a 6 year period. All patients were anaesthetised by a single anaesthetist (ACW). The patient's age, previous surgery, type of anaesthetic, anaesthetic agents, and volumes were noted.
Akinesia was assessed on a range of $0-4$ (0 no movement, 1 flicker, 2 some movement, 3 moderate movement, 4 full movement). Reaction to the LA block was graded from 1-4 (1 being no pain felt, 2 no comment, 3 moderate discomfort, and 4 severe pain).

Surgery was divided into vitrectomy, retinopexy with or without vitrectomy, and scleral buckling surgery. Patients' reaction to surgery was graded 1-4 (1 minor discomfort-for example, to subconjunctival injection, 2 mild, 3 moderate, 4 severe-would not like LA again). Anaesthetic complications affecting surgery were noted and use of peroperative sedation.

Data were analysed using STATVIEW software. Non-parametric data are presented as proportions with percentage and 95\% confidence intervals (95\% CI). These were analysed using $\chi^{2}$ test. Parametric data were analysed using the unpaired two tail $t$ test. Confidence intervals omitted from the text are shown in Table 1.

\section{Results}

In all, 1221/1479 (82\%) patients had local anaesthesia for VR surgery (Table 1). Operations under LA included 436/1221 (35.7\%) vitrectomies, 545/1221 (44.7\%) retinopexies with or without vitrectomy, and 240/1221 $(19.5 \%)$ buckling procedures. LA was used in $203 / 258$ redo procedures $(79 \%$; 95\% CI $76.5-$ $81.3 \%)$.

Patients under 35 years (younger) were more likely to have a general anaesthetic, 87/147 (59.1\%: 95\% CI 54.0-64.5\%), those over 35 years (older) were more likely to have LA, 1161/1332 (87.1: 95\% CI 86.1-88.1; p<0.01) (Fig 1). There was no difference in peroperative pain $(10.6 \% v 11.0 \%)$ or need for sedation $(10.4 \% v 7.6 \%)$ in younger or older patients, respectively. However, younger patients were more likely to feel discomfort during the local block $(31.9 \%$ v $14.9 \% ; \mathrm{p}<0.01)$ and have more kinesia $(17.0 \%$ v $6.3 \%$; $\mathrm{p}<0.01)$.

Of the 1221 LA blocks 164 (13.4\%) were intraconal only, $130(10.6 \%)$ were peribulbar only, and $927(75.9 \%)$ were a combination of both. The volumes of LA used for inferotemporal, medial, and top up injections were: 5.3 $\mathrm{ml}$ (SD 0.53), $3.14 \mathrm{ml}$ (1.31), $0.7 \mathrm{ml}$ (1.78), respectively. The total volumes given for vitrectomy, retinopexy with or without vitrectomy, and buckling surgery were $7.94 \mathrm{ml}(1.6), 8.52$ $\mathrm{ml}$ (1.8), and $12.58 \mathrm{ml}$ (2.98), respectively $(\mathrm{p}<0.001)$. The proportion of patients feeling pain (score 3-4) from the anaesthetic injection was significantly lower when bicarbonate was added, falling from $94 / 408(23.0 \% ; 95 \%$ CI $21.0-25.1 \%)$ to $178 / 1813(11.6 \%$; $95 \%$ CI $10.33-12.9, \mathrm{p}<0.01)$. More patients having redo surgery following buckling felt pain 
Table 1 Demographic data

\begin{tabular}{|c|c|c|c|}
\hline & No & $\%$ & $95 \% C I(\%)$ \\
\hline Patients & 1479 & 100 & \\
\hline \multicolumn{4}{|l|}{ Type of anaesthetic } \\
\hline GA & 258 & 17.4 & $15.1-19.8$ \\
\hline LA & 1221 & 82.6 & $81.7-83.5$ \\
\hline \multicolumn{4}{|l|}{ Previous VR surgery } \\
\hline LA & 1221 & 16.6 & $15.5-17.7$ \\
\hline GA & 259 & 21.2 & $18.6-23.7$ \\
\hline \multicolumn{4}{|l|}{ Local anaesthetic data } \\
\hline \multicolumn{4}{|l|}{ Type of LA } \\
\hline Intracone & 164 & 13.4 & $10.7-16.1$ \\
\hline Peribulbar & 130 & 10.5 & $7.9-13.3$ \\
\hline Combination & 927 & 75.9 & $74.5-77.3$ \\
\hline \multicolumn{4}{|l|}{ Anaesthetic agents used } \\
\hline Lignocaine + bupivacaine & 408 & 33.4 & $32.1-34.8$ \\
\hline Lignocaine $+\mathrm{HCO}$ & 92 & 7.5 & $6.8-8.3$ \\
\hline Lignocaine + bupivacaine $+\mathrm{HCO}$ & 620 & 50.8 & $49.3-52.2$ \\
\hline Lignocaine + ripovcaine & 101 & 8.3 & $7.5-9.1$ \\
\hline \multicolumn{4}{|l|}{ Type of operation } \\
\hline Vitrectomy & 436 & 35.7 & $33.4-38.0$ \\
\hline Retinopexy +/- vitrectomy & 545 & 44.7 & $42.5-46.7$ \\
\hline Scleral buckling & 238 & 19.5 & $16.9-22.1$ \\
\hline \multicolumn{4}{|l|}{ Pain on injection } \\
\hline No pain & 129 & 10.5 & $7.8-13.2$ \\
\hline No response & 901 & 73.7 & $72.3-75.7$ \\
\hline Mild & 174 & 14.2 & $11.6-16.9$ \\
\hline Severe & 17 & 1.3 & $-1.4-4.2$ \\
\hline \multicolumn{4}{|l|}{ Pain of operation } \\
\hline No pain & 1085 & 88.9 & $88.0-89.8$ \\
\hline Sensation & 69 & 5.7 & $5.0-6.3$ \\
\hline Mild pain & 57 & 4.8 & $4.1-5.3$ \\
\hline Moderate pain & 7 & 0.57 & $0.36-0.79$ \\
\hline Severe pain & 2 & 0.2 & $0-0.3$ \\
\hline \multicolumn{4}{|l|}{ Sedation } \\
\hline No sedation & 1126 & 92.2 & $91.4-93.0$ \\
\hline Sedation & 95 & 7.8 & $5.0-10.5$ \\
\hline Any kinesia & 87 & 7.1 & $6.4-7.9$ \\
\hline Chemosis & 61 & 5.0 & $2.2-7.8$ \\
\hline Additional LA & 188 & 16.9 & $15.8-19.3$ \\
\hline \multicolumn{4}{|l|}{ Mean age of patients (years) } \\
\hline All & 63.5 & Range $10-103$ & \\
\hline $\mathrm{LA}$ & 63.5 & Range 19-103 & \\
\hline \multirow[t]{2}{*}{ GA } & $45.9^{\star}$ & Range 10-87 & \\
\hline & & & $\mathrm{p}<0.01$ \\
\hline
\end{tabular}

during the anaesthetic $(41 / 203 ; 20.14 \% ; 95 \%$ CI $16.1-23.1 \%$ v 153/1081; $15.03 \%$; 95\% CI 13.9-16.1, p<0.05). Peroperative top up anaesthesia was given in 193/1221 (15.8\% 95\% CI $14.8-16.8 \%)$; this rose to $159 / 240(66.2 \%$ 95\% CI 63.2-69.2\%) patients having buckling surgery.

Compete akinesia was noted in 1134 patients (92.8\% 95\% CI 92.1-93.6), slight twitch in $79(6.74 \%: 95 \%$ CI $5.8-7.2)$, moderate kinesia in seven $(0.6 \%$ : 95\% CI $0.4-0.8 \%)$, and full movement in one $(0.08 \%: 95 \%$ CI $0-0.2 \%)$.

PEROPERATIVE PAIN

Pain scores of $0,1,2,3,4$ were reported by $1085 / 1221 \quad(88.9 \% ; 95 \%$ CI $88.0-89.8 \%)$ 69/1221 (5.7\%; 95\% CI 5.0-6.3\%), 57/1221 $(4.79 \% ; 95 \%$ CI $4.1-5.3 \%), 7 / 1221 \quad(0.57 \%$ 95\% CI $0.36-0.79)$, and $2 / 1221(0.2 \% ; 95 \%$ CI 0-0.3\%) patients, respectively.

The percentage of patients with any pain during surgery varied with operation and were $17 / 435$ (3.9\%; 95\% CI 2.9-4.8), 25/543 $(4.6 \% ; 95 \%$ CI $3.7-5.5)$, and $24 / 240(10.0 \%$ 95\% CI 8.1-11.9) for vitrectomy, retinopexy with or without vitrectomy, and buckling surgery respectively. Buckling surgery was more painful $(\mathrm{p}=0.002)$ and more sedation was required in $28 / 240(11.67 \%, 95 \%$ CI $9.6-$ 13.7), compared with vitrectomy $26 / 436$ (5.9\%, 95\% CI 4.8-7.1), ( $\mathrm{p}=0.016)$ (Table 1).

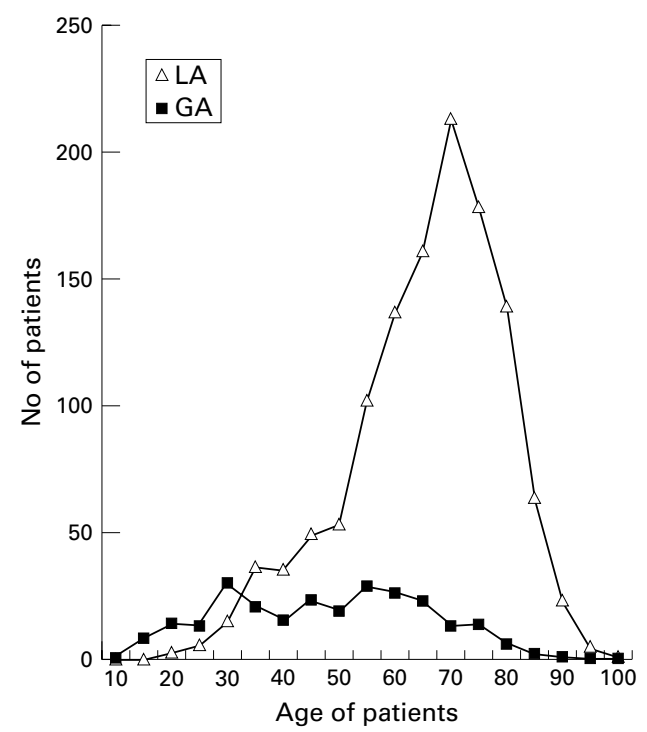

Figure 1 Histogram of patients' age versus type of anaesthesia used for vitreoretinal surgery. $59.1 \%$ of patients aged $<35$ years had general anaesthesia $(G A) ; 87 \%$ of patients aged $>35$ years had local anaesthesia ( $L A)$.

There was also no difference in pain between primary $(51 / 1081 ; 5.0 \% 95 \%$ CI $4.3-5.69)$ and redo surgery $(16 / 203 ; 7.9 \% \quad 95 \%$ CI $5.9-9.7 \%)$.

SEDATION

Sedation was given to $95 / 1121(7.8 \%, 95 \%$ CI $5.0-10.5 \%)$ of patients. Sedation was used in $41 / 545$ (5.96\%; $95 \%$ CI $4.8-7.1 \%$ ) of vitrectomies, in $26 / 436(7.52 \%$; $95 \%$ CI $6.3-8.7 \%)$ patients with retinopexy with or without vitrectomy and in $28 / 240(11.67 \% ; 95 \%$ CI 9.6-13.7\%) patients needing buckling surgery $(\mathrm{p}<0.01)$. Sedation was required in $16 / 203$ $(7.9 \% ; 95 \%$ CI $6.0-9.8 \%)$ patients under going redo surgery, compared with 79/1018 $(7.8 \% ; 95 \%$ CI $6.9-8.6 \%)$ of those undergoing primary surgery $(p>0.1)$. Patients needing sedation were given more LA $9.8 \mathrm{ml}$ (SD 3.03) compared with those not needing sedation $9.05 \mathrm{ml}(2.6, \mathrm{p}<0.005)$ (Table 1$)$.

\section{COMPLICATIONS}

No patient suffered a retrobulbar haemorrhage or ocular perforation in this series: 64/1221 (5.24\%; 95\% CI 4.6-5.8\%) patients had moderate to severe chemosis, none of which prevented surgery taking place, 4/1221 $(0.33 \% ; 95 \%$ CI $0.2-0.5 \%)$ patients had significant bradycardia, 9/1221 (0.74\%; 95\% CI $0.4-0.9 \%$ ) had moderate claustrophobia, $1 / 1221(0.08 \% ; 95 \%$ CI $0-0.016 \%)$ severe claustrophobia and was given propofol, and one operation was cancelled $(0.08 \% ; 95 \%$ CI 0-0.016\%) (Table 1).

\section{Discussion}

In this series we have been able to assess the results of LA for VR surgery in 1221 cases given by a single anaesthetist (ACW) and have found it to be a well accepted and useful technique. The high levels of patient satisfaction in this study are similar to the study of Rao et $a l^{4}$ with $93.1 \%$ of patients happy to have LA again. 
Using a combined peribulbar and intraconal technique, good analgesia and good akinesia were obtained in $87.9 \%$ and $98.0 \%$ respectively. When bicarbonate was added to the LA solution the proportion of patients with discomfort during anaesthesia fell to $11.6 \%$. These high levels of akinesia and anaesthesia are comparable with other methods of anaesthesia. ${ }^{12} 16$ A top up rate of $32 \%$ has been reported with peribulbar and retrobulbar techniques, ${ }^{8}$ in our series it was $16 \%$ rising to $66 \%$ in buckling surgery.

Redo operations may be a contraindication to LA. However, in this series we performed $79 \%$ of second procedures under LA, a higher proportion of those with previous buckling surgery felt some pain during the LA $(11.6 \% v$ $10.5 \%$ ); however, peroperative pain was similar in both groups $(7.8 \%$ v $5.1 \%)$. Midazolam was used in 95 patients; in our experience sedation was useful in controlling claustrophobia (10/ 1221).

Kirkby et $a l^{5}$ commented that a oculocardiac response and retrobulbar haemorrhage may prevent surgery on urgent cases. In this series, no cases of retrobulbar haemorrhage or globe perforation occurred, significant bradycardia was noted in four patients, chemosis occurred in 61 of our patients but this was never sufficient to prevent surgery.

In this department LA was originally used for postoperative analgesia; this led to its use for high risk patients and shorter procedures. Now careful patient selection and counselling have enabled the use of LA for $96 \%$ of VR procedures with high rates of surgeon and patient satisfaction.

1 Hamilton R, Gimble H, Strunin L. Regional anaesthesia for 12000 cataract extraction and intraocular lens implantation procedures. I Can Anaesth 1988;35:615-23.

2 Hodgkins P, Luff A, Morrell A, et al. Current practice of cataract extraction and anaesthesia. Br f Ophthalmol 1992; 76:323-6.

3 Eke T, Thompson J. The national survey of local anaesthesia for ocular surgery. II. Survey methodology and current practice. Eye 1999;13:196-204.

4 Rao P, Wong D, Groenewald C, et al. Local anaesthesia for vitreoretinal surgery: a case control study of 200 cases. Eye 1998;12:407-11.

5 Kirkby G, Benson M, Callear A, et al. Local anaesthesia for vitreoretinal surgery: a case control study of 200 cases. Eye 1999;13:122.

6 Javitt J, Addiego R, Friedberg H, et al. Brain stem anaesthesia after retrobulbar block. Ophthalmology 1987;94:718-23.

7 Duker J, Belmont J, Benson W, et al. Inadvertent globe perforation during retrobulbar and peribulbar anesthesia. Ophthalmology 1991;98:519-26.

8 Demediuk O, Dhaliwal R, Papworth D, et al. A comparison of peribulbar and retrobulbar anesthesia for vitreoretinal surgical proceedures. Arch Ophthalmol 1995;113:908-13.

9 Davis DB 2nd, Mandel M. Posterior peribulbar anesthesia, an alternative to retrobulbar anesthesia. 7 Cataract Refract Surg 1986;12:182-4.

10 Benedetti S, Agostini A. Peribulbar anesthesia for vitreoretinal surgery. Retina 1994;14:277-80.

11 Batterbury $\mathrm{M}$, Wong $\mathrm{D}$, Williams $\mathrm{R}$, et al. Peribulbar anaesthesia: failure to abolish the oculocardiac reflex. Eye 1992;6:293-5.

12 Stevens J, Franks W, Orr G, et al. Four-quadrant local anaesthesia technique for vitreoretinal surgery. Eye 1992;6: 583-6.

13 Kwok A, Van Newkirk M, Lam D, et al. Subtenons anesthesia in vitreoretinal surgery. Retina 1999;19:291-6.

14 Yildirim R, Aras C, Ozdamar A, et al. Silicone oil removal using self-sealing corneal incision under topical anesthetic. Ophthalmic Surg Lasers 1999;30:24-6.

15 Yepez J, Yepez J, Arevalo J. Topical anesthesia in posterior vepez J, Yepez J, Arevalo J. Topic

16 Mein C, Woodcock M. Local anesthesia for vitreoretinal surgery. Retina 1990;10:47-9. 